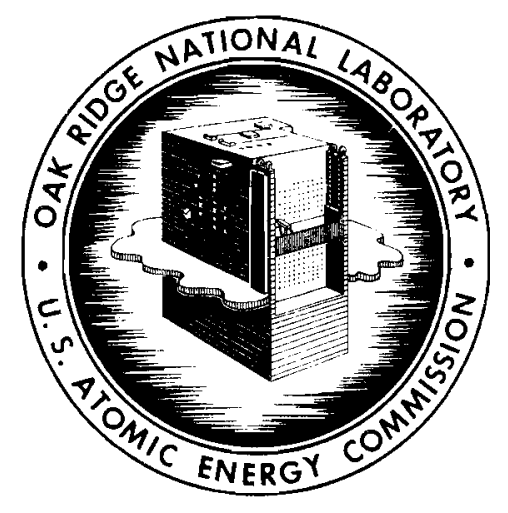

OAK RIDGE NATIONAL LABORATORY

operated by

UNION CARBIDE CORPORATION

for the

U.S. ATOMIC ENERGY COMMISSION

ORNL-TM- 75

COPY NO. -

9

DATE - November 30, 1961

\title{
A LABORATORY GAS-CIRCULATING PUMP
}

B. McNabb, Jr., and H, E. McCoy, Jr。

\section{ABSTRACT}

A pump has been developed for pumping carbon dioxide in a closed lcop without introducing impurities. This pump will give flow rates of up to 3 liters/min and wili develop a working pressure of over $70 \mathrm{~mm} \mathrm{Hg}$. No wear was observed after $2000 \mathrm{hr}$ of testing. It is felt that this pump is more desirable for this application than those developed by other experimenters for two reasons: (1) the relativeiy inexpensive construction of the pump and the associated eiectronic circuit, and (2) the iow cofficient of frietion between the piston and the cyinder wall. Variolis modifications are suggested which will make this pump satisfactory for cther applications.

\section{NOTICE}

This document contains information of a preliminary nature and was prepared primarily for internal use at the Oak Ridge National Laboratory. It is subject to revision or correction and therefore does not represent a final report. The information is not to be abstracted, reprinted or otherwise given public dissemination without the approval of the ORNL patent branch, Legal and Information Control Department. 


\section{A LABORATORY GAS-CIRCULATING PUMP}

TNTRODUCTION

The need to circulate gases and liquids on a relatively small laboratory scale without introducing impurities often arises. In some cases, the fluid to be circulated is highly corrosive and all metallic components must be eliminated. Hence, pumps utilizing metal diaphragms are not satisfactory for this application. In other cases, the fluid is not corrosive but the particular application requires that no impurities such as air, mercury, or carbonaceous vapors be introduced into the system. Pumps which have packings or lubricants exposed to the circulating fluid are unsatisfactory in this instance. Pumps which utilize mercury, such as the Toepler pump, are also undesirable because of the small partial pressure of mercury which is added to the circulating media.

Several experimenters ${ }^{1-5}$ have developed pumps which circumvent the difficulties just described. These pumps all have several common features. They are of the electromagnetic type with the piston being the plunger of a solenoid. The piston is a soft iron rod sealed in glass. The cylinder is also made of glass and is surrounded by a solenoid coil. Several different electrical circuits are used for pulsing current to the solenoid coil.

The particular application of a circluating pump under discussion is that of recirculating carbon dioxide in a closed system at temperatures less than $100^{\circ} \mathrm{F}$ for periods as long as $1000 \mathrm{hr}$. It is necessary that the gas not be contaminated with carbonaceous vapors, air, or mercury vapors. The total

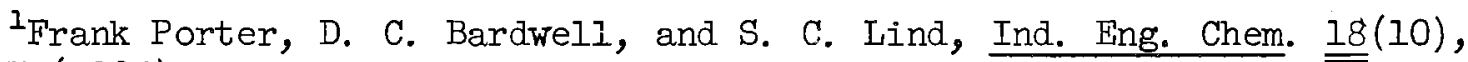
1086-7 (1926).

${ }^{2}$ W. S. Funnel and G. I. Hoover, J. Phys. Chem. 31, 1099 (1927).

${ }^{3}$ R. Livingston, J. Fhys. Chem. 33, 955 (1929).

${ }^{4}$ Von W. Brenschede, "Eine elektromagnetische Kolbenpurape fürLaboratoriumszwecke," Z. physik. Chem. 178A, 74-5 (1937).

${ }^{5}$ N. S. Corney, H. B. F. Gow, and R. B. Thomas, A Glass Enclosed Gas Circulating Pump, AERE C/M 364 (Feb., 1959).
} 
pressure drop through the system is of the order of a few centimeters of water due to the presence of reagents for removing reaction products from the circulating gas. Since a considerable range of flow rates is desired, the pump speed must be variable. The design of one of the electromagnetic pumps described in the literature was not duplicated for two major reasons. (1) The moving parts are glass against glass; thus, the sliding friction is quite high and leads to rapid wearing of the pump. Dimensional tolerances are also quite difficult to control and the developed head and flow rates of such pumps are relatively low. It was felt that the design of the piston could be improved without introducing impurities into the system. (2) The electrical circuits are relatively complex and lack the desired flexibility.

The following report is a brief description of the pump which was developed for this specific application. Modifications are suggested which yield this pump suitable for other applications.

GENERAL DESCRIPTION

The pump is composed primarily of a piston of magnetic material inside a smooth bore glass tube approx $3 / 4-i n$. ID and 12 in. long. It has two glassball check valves in series, one inside the piston and one above it to prevent backstreaming on the downstroke of the piston. These ball check valves are commercially available from Laboratory Glass, Inc, Vineland, New Jersey. A solenoid coil is placed on the outside of the glass tube to move the piston. Figures 1 and 2 show, respectively, a general view and a schematic representation of the pump with the coil in operating position. The spring at the bottom of the cylinder serves to absorb the impact of the reciprocating piston. Figure 3 is an exploded view of the piston showing the glass-ball check valve, the two end plugs or bushings of nylon, and the iron cylinder to make the piston magnetic. Nylon was chosen for this application for several reasons which include its availability, good machinability, low coefficient of friction, ${ }^{6}$ and inertness and stability ${ }^{7}$ in carbon dioxide at approx $100^{\circ} \mathrm{F}$.

\footnotetext{
${ }^{6}$ I. J. Goodman, Polymer Sci. 13, 175 (1954).

${ }^{7}$ D. E. Floyd (ed.), Polyamide Resins, pp 9-31, Reinhold Publishing Corp., New York, 1958.
} 


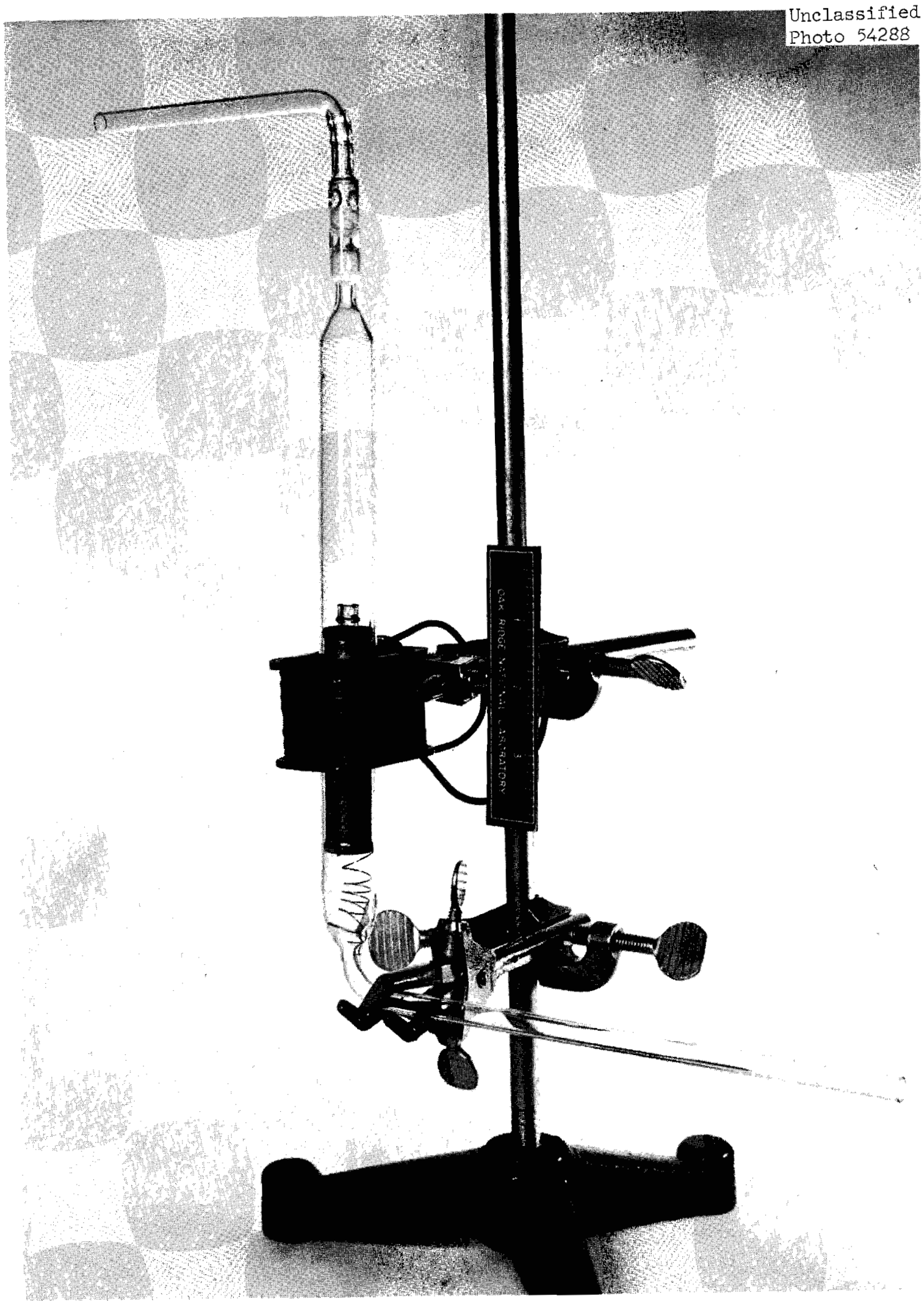

Fig. 1. General View of Pump. 


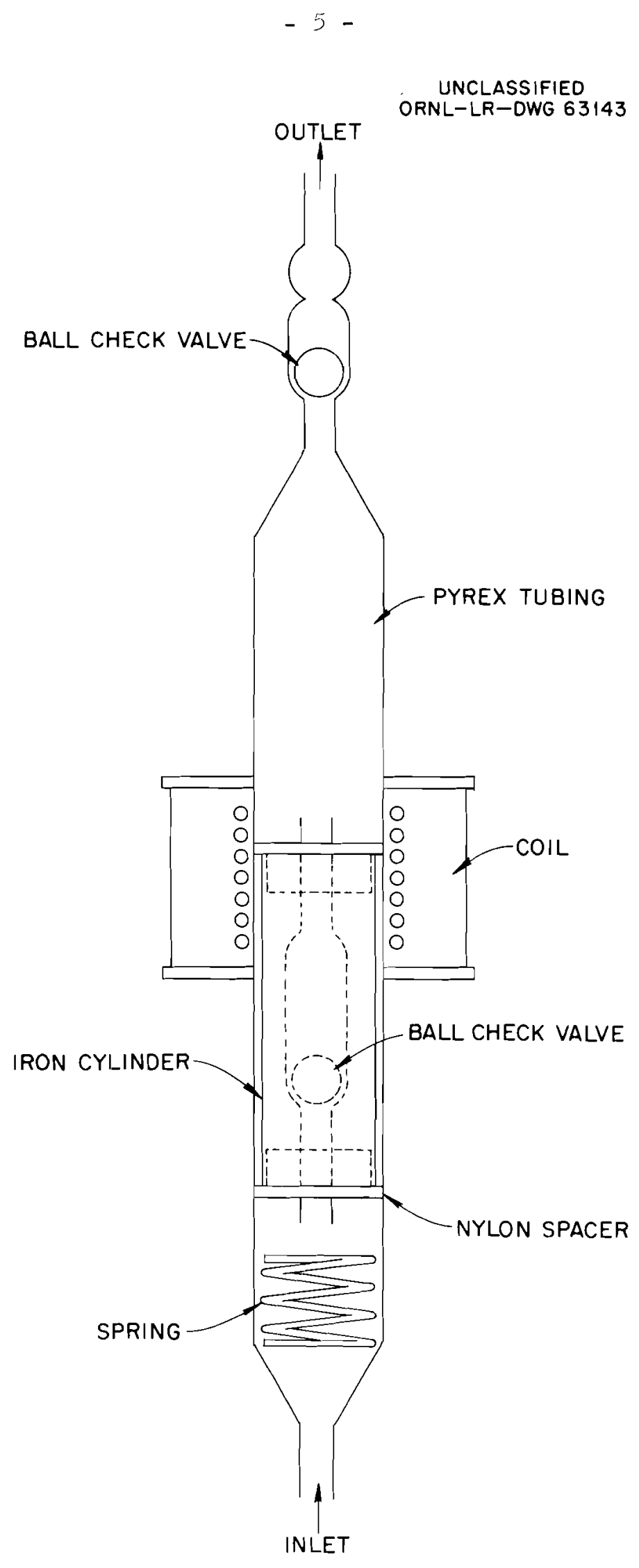

Fig. 2. Schematic Drawing of Pump. 


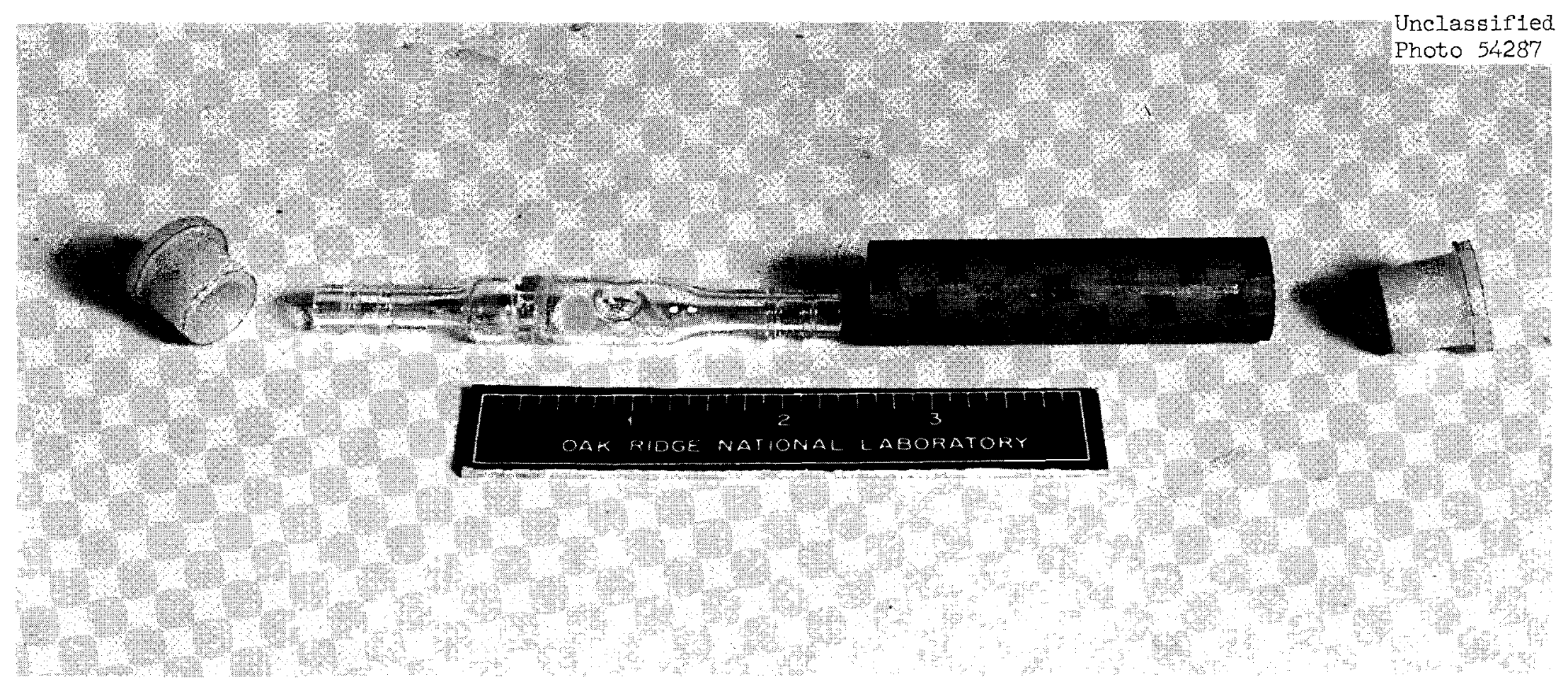

Fig. 3. Exploded View oi Piston. 
The heat distortion temperature of nylon is $360^{\circ} \mathrm{F}$ and it will withstand continuous service at $300^{\circ} \mathrm{F} .{ }^{8}$ Figure 4 is a close-up of the motor which controls the speed of the pump. The $115-\mathrm{v}$ alternating-current motor was manufactured by the Bodine Electric Company, Chicago, Illinois. It has a speed of $5000 \mathrm{rpm}$ at full power, but comes equipped with a 20:1 speed reducer which gives a maximum shaft speed of $250 \mathrm{rpm}$. The speed of the motor is varied by a Variac. The cam is Teflon and was made by drilling a piece of 3/4-in. -diam rod off-center. The coil is operated on the normally open contacts of the microswitches and a 150-w light bulb is connected in series with the coil on the normally closed contacts. This arrangement prevents the current to the coil from dropping to zero and, hence, the piston does not drop to the bottom of the cylinder on each stroke. The clip leads shown in Fig. 4 are used for making connections to the solenoid coil and the impulse counter.

\section{OPERATIONAL CHARACIEERISTICS}

Figure 5 shows a general layout of the pump and the auxiliary equipment used in testing the pump. The Variac is used to control the speed of the motor which in turn controls the speed of the pump. The Precision Wet Test meter, manufactured by the Precision Scientific Company, Chicago, Illinois, was used to measure the volume of gas circulated by the pump. The impulse counter counts the number of cycles of the pump. The light bulb which was used to reduce the current is not shown in Fig. 5.

With a system pressure of 1 atm, flow rates of gas of 3 liters/min are easily attainable with this pump and a head of $70 \mathrm{~mm} \mathrm{Hg}$ can be overcome readily. As the pressure which must be overcome increases, the power to the coil must be increased to maintain the same flow rate. The particular pump tested has a lower operating pressure limitation of about $1 \mathrm{~mm} \mathrm{Hg}$, but seems to work well up to gas pressures in excess of 1 atm.

\footnotetext{
${ }^{8} \mathrm{Almac}$ Plastics, Inc., 600 Broadway, New York 12, New York, 1960 catalog.
} 


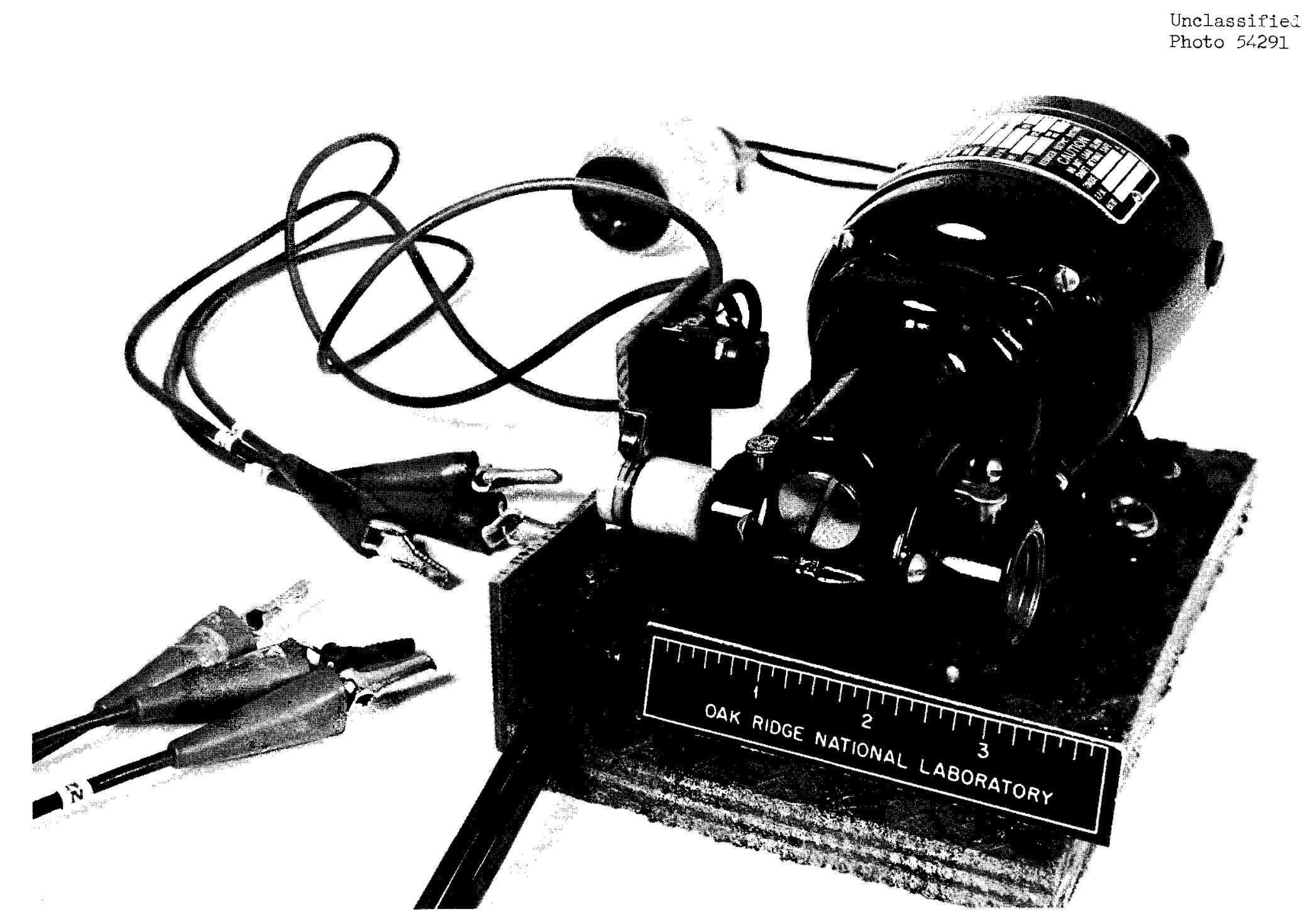

Fig. 4. Motor and Switches for Regulating Pump Speed. 


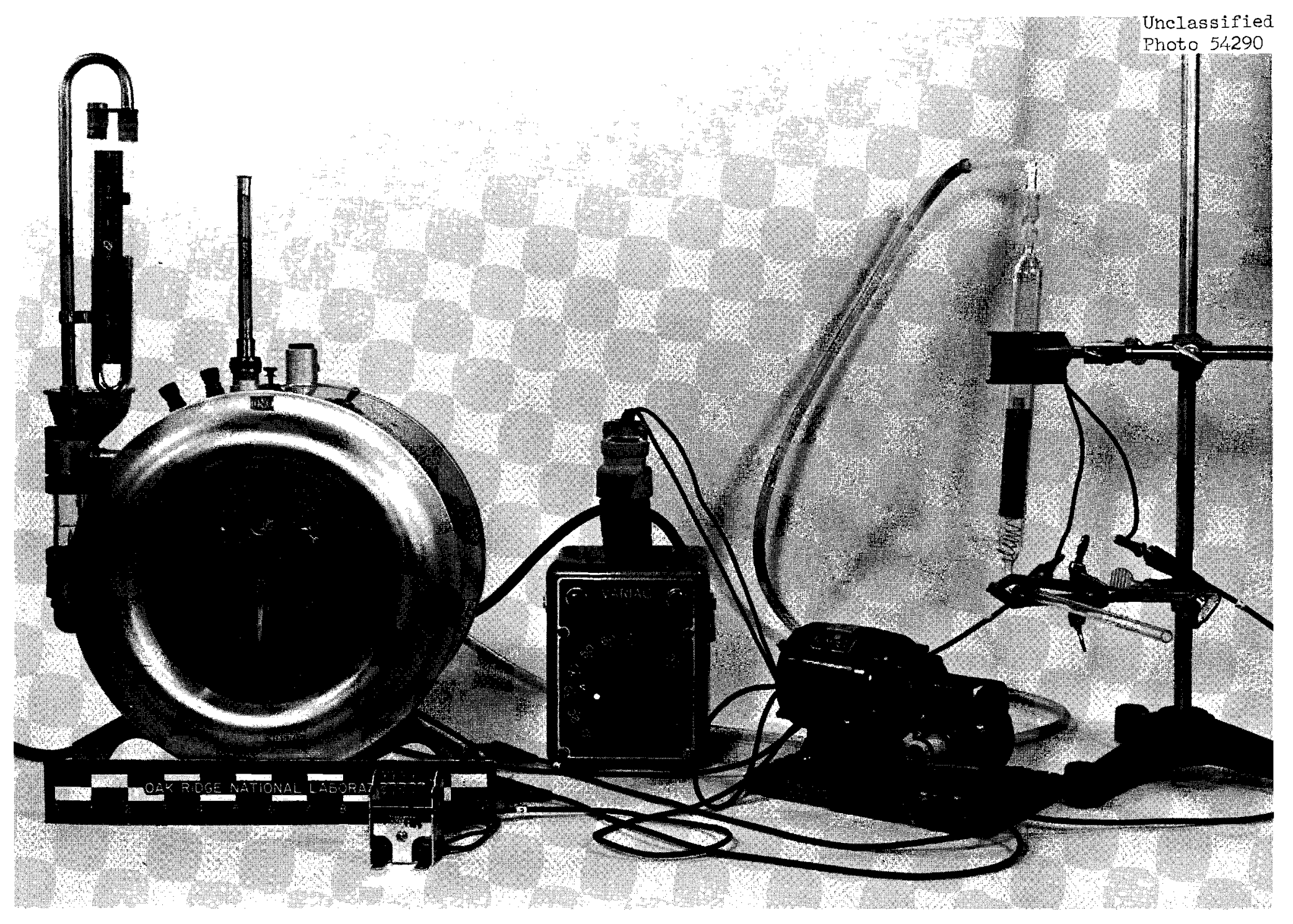

Fig. 5. Equipment for Testing Pump. 
It is quite difficult to measure flow rates in a system of this nature without introducing an appreciable pressure drop. The pulsating nature of the flow makes the problem even greater. The possibility of using the piston displacement and the impulse rate to obtain the volumetric flow rate was investigated. This method was found to be satisfactory for air at atmospheric pressure, but could not be investigated at lower pressures since the flow meter would not operate at pressures less than atmospheric.

It was found that the pump could be used to pump liquids such as water and other low-viscosity liquids. However, the power requirements are much greater than for gases. Dimensional tolerances also become more critical than those required for pumping gases. For example, it was found that the same pump which gave a one-to-one correlation between piston displacement and volume of gas pumped gave only a three-to-one correlation for water.

The test pump was operated in excess of $2000 \mathrm{hr}$ using air as a test fluid, and no evidence of wear was observed. It is emphasized that attempts have not been made to optimize the pump design with respect to the coil and the magnetic properties of the piston. Considerable improvement in performance might be obtained if this were done. However, the pump which was tested was entirely satisfactory for the intended application.

\section{SUGGESTED ALTERATIONS IN DESIGN}

The pump which has been described in detail in this report was designed for the purpose of pumping carbon dioxide in a closed loop at temperatures of less than $100^{\circ} \mathrm{F}$. This gas is not corrosive at these conditions and, hence, the iron core of the piston and the spring at the bottom of the cylinder could be exposed. If operating conditions did not permit this, both of these components could be enclosed in a nonvolatile plastic.

Figures 6, 7, and 8 show suggested alternate pump designs which have been found to operate satisfactorily and may be more desirable for some applications. In the arrangement shown in Fig. 6, the inlet side of the pump is modified. No particular operational advantages result from this modification, but this physical layout may be more desirable in some cases. In Figs. 7 and 8 , the pump operates in the horizontal position. Hence, two coils are required to 


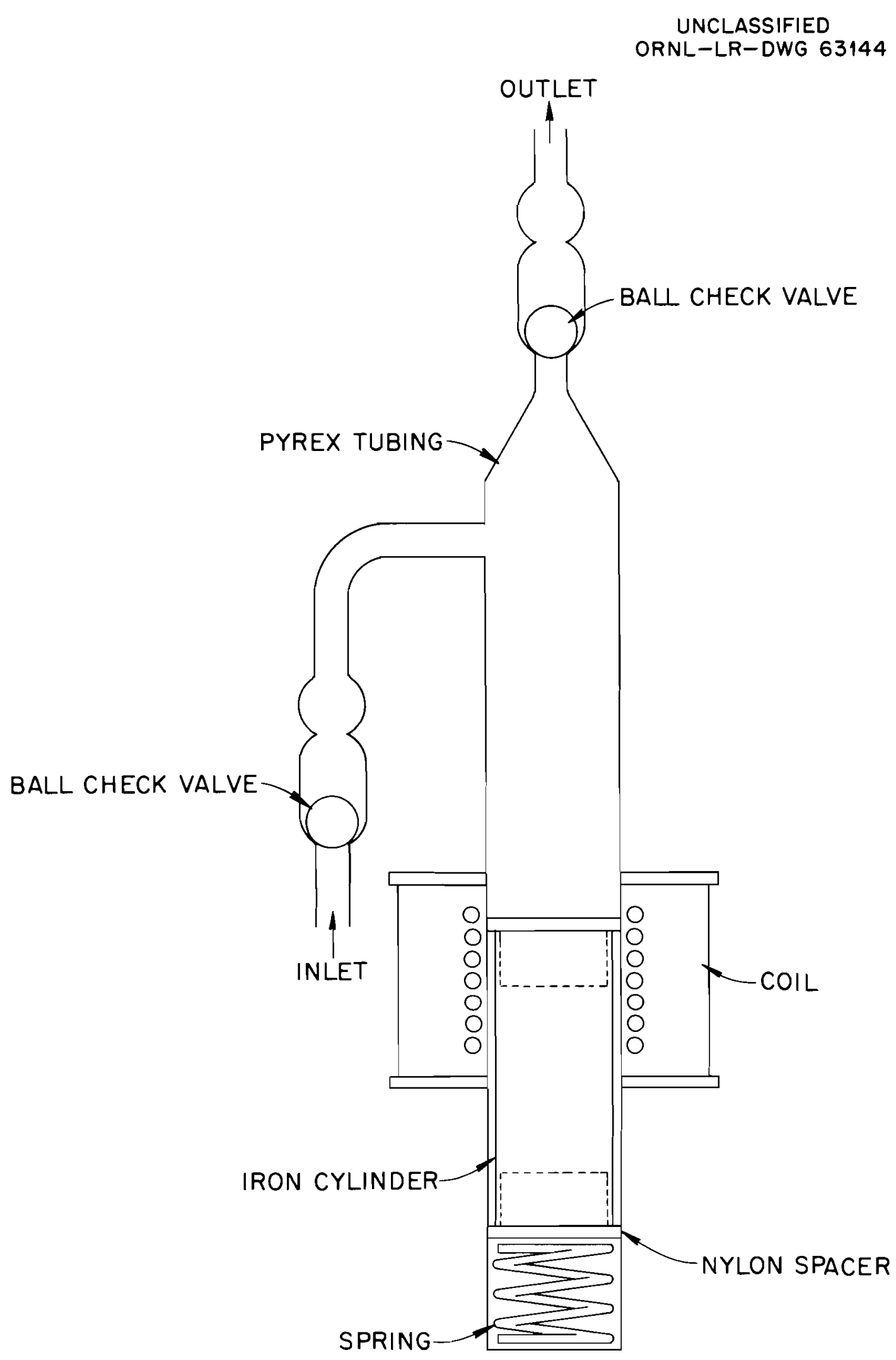

Fig. 6. Alternate Design with Inlet and outlet on Same End of Pump. 
UNCLASSIFIED

ORNL-LR-DWG 63145

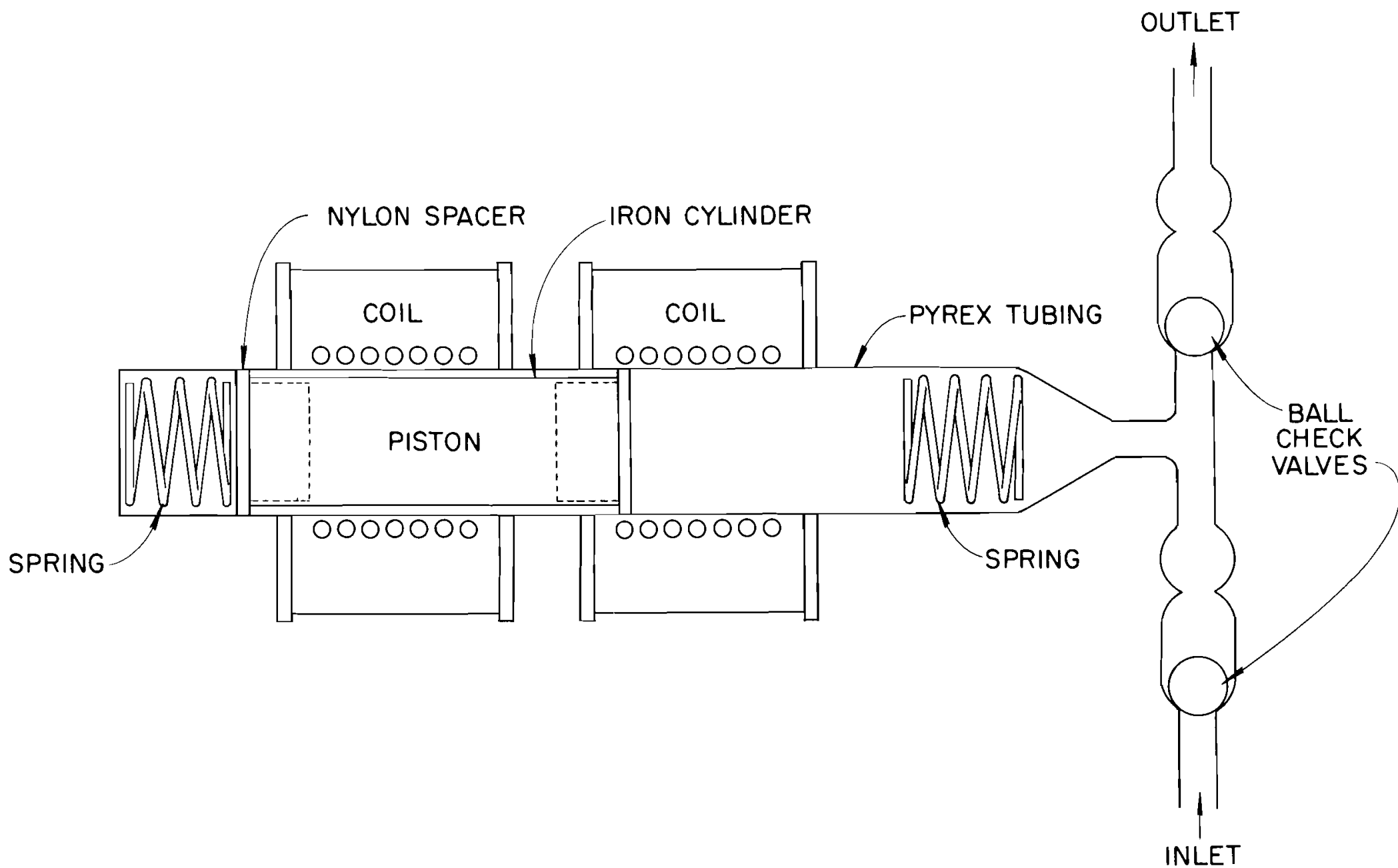

1

Fig. 7. Alternate Design with Pump Operating in Horizontal Position. 


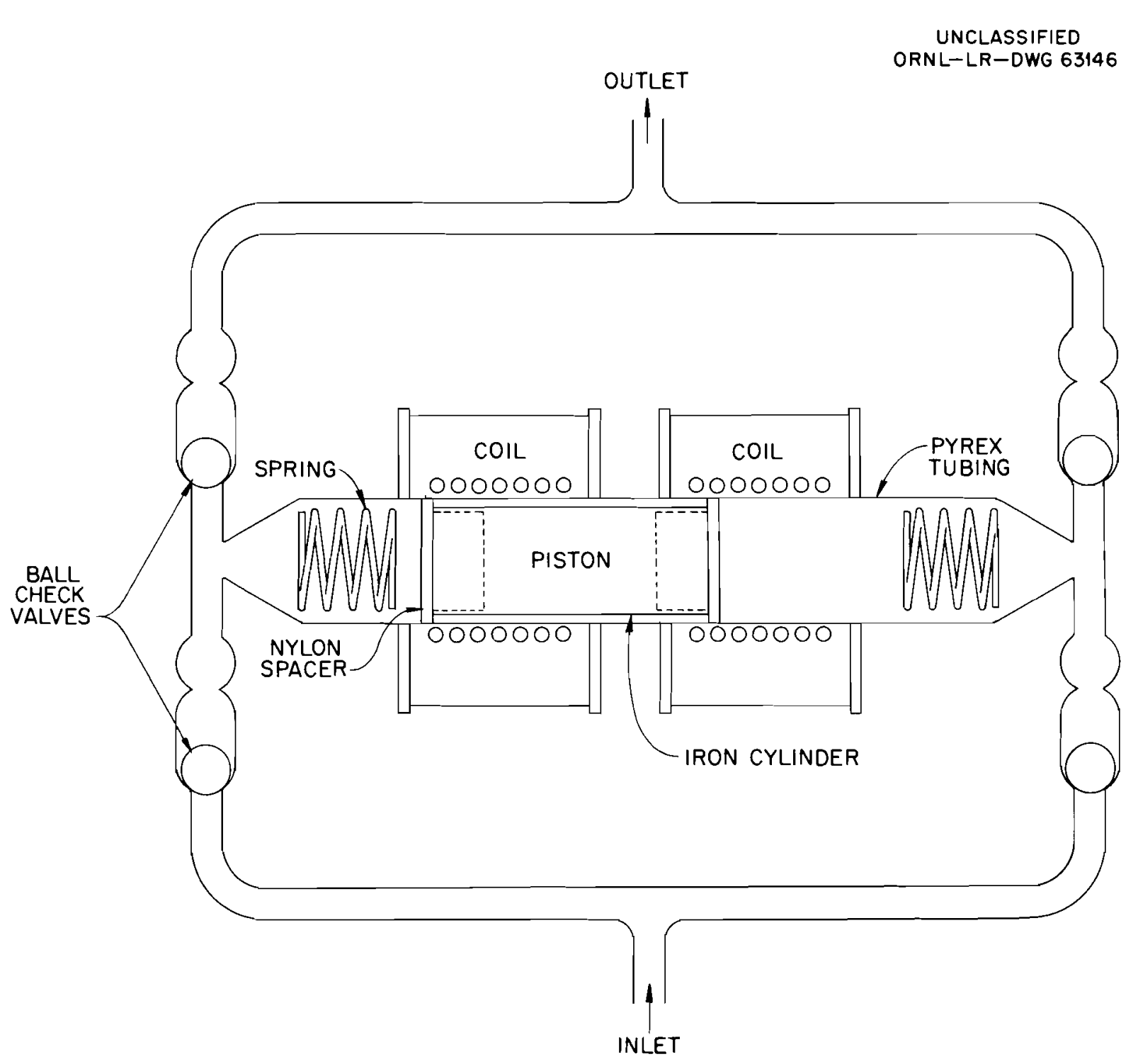

Fig. 8. Alternate Design with the Pump Operating in the Horizortal Position as a Double-Acting Pump. 
operate the piston. The pump in Fig. 8 is a double-acting pump in that pumping occurs when the piston moves either to the right or to the left. This is not an exhaustive listing of modifications as numerous others exist for particular applications.

\section{CONCLUSIONS}

A pump has been developed for pumping carbon dioxide in a closed loop at less than $100^{\circ} \mathrm{F}$ without introducing contamination. This pump will give flow rates of up to 3 liters/min and will develop a working pressure of over $70 \mathrm{~mm} \mathrm{Hg}$. After some $2000 \mathrm{hr}$ of test time, the pump did not show any detectable wear. This pump is more desirable for this application than those developed by the other experimenters for two reasons: (1) the relatively inexpensive construction of the pump and the associated electronic circuit and (2) the low coefficient of friction between the piston and the cylinder wall. Various modifications can be made which will increase the number of applications for which this pump can be used. 


\section{DISTRIBUTION}

1-2. Central Research Library

3. Document Reference Section

4-8. Laboratory Records

9. Laboratory Records, RC

10-24. Division of Technical Information Extension

25. Research and Development Division, ORO

26. G. M. Adamson, Jr.

27. J. C. Amos

28. R. J. Beaver

29. J. O. Betterton, Jr.

30. B. S. Borie

31. J. V. Cathcart

32. G. W. Clark

33. R. E. Clausing

34. J. H. Coobs

35. W. H. Cook

36. J. E. Cunningham

37. J. H. DeVan

38. D. A. Douglas, Jr.

39. J. H Frye, Jr.

40. R. J. Gray

41. J. P. Hammond

42. W. O. Harms

43-47. M. R. Hill

48. E. E. Hoffman

49. L. D. Hulett

50. $\mathrm{H}$. Inouye
51. C. R, Kennedy

52. C. F. Leitten, Jr.

53. A. L. Lotts

54. T. S. Lundy

55. H. G. MacPherson

56. W. D. Manly

57. W. R. Martin

58. R. W. McClung

59-68. H. E. McCoy, Jr.

69. D. L. McElroy

70. C. J. McHargue

71. B, McNabb, Jr.

72. C. S. Morgan

73. P. Patriarca

74. M. L. Picklesimer

75. J. L. Scott

76. M. J. Skinner

77. G. M. Slaughter

78. G. P. Smith, Jr.

79. E. E. Stansbury

80. R. L. Stephenson

81. A. Taboada

82. W. C. Thurber

83. J. T. Venard

84. M. S. Wechsler

85. J. R. Weir, Jr.

86. R. O. Williams

87. J. W. Woods

88. H. L. Yakel, Jr. 